\title{
Parenteral nutrition-associated hyperglycemia in noncritically ill inpatients is associated with higher mortality
}

\author{
Sofia Sarkisian BSc RD ${ }^{1}$, Tanis R Fenton RD PhD ${ }^{1,2}$, \\ Abdel Aziz Shaheen MD MPH ${ }^{1,3}$, Maitreyi Raman MD MSc FRCPC ${ }^{1,3}$
}

\begin{abstract}
S Sarkisian, TR Fenton, AA Shaheen, M Raman. Parenteral nutrition-associated hyperglycemia in noncritically ill inpatients is associated with higher mortality. Can J Gastroenterol 2010;24(7):453-457.
\end{abstract}

BACKGROUND: Hyperglycemia is a marker of poor clinical outcomes in studies evaluating hospitalized critically ill patients.

OBJECTIVES: To identify whether glycemic control is associated with health outcomes including acute coronary events, renal failure, infection, hospital length of stay, intensive care unit (ICU) admission, sepsis and mortality in noncritically ill patients administered parenteral nutrition (PN), and to compare the current standard of care for glucose monitoring at the Foothills Medical Centre (Calgary, Alberta) with the 2009 American Society of Parenteral and Enteral Nutrition guidelines.

METHODS: A retrospective chart review of 100 adult (18 years of age or older) non-ICU inpatients who received PN for seven days or longer at the Foothills Medical Centre was conducted.

RESULTS: Seventeen patients (17\%) had a mean blood glucose level of $10.0 \mathrm{mmol} / \mathrm{L}$ or greater. PN patients with a mean blood glucose level of $10 \mathrm{mmol} / \mathrm{L}$ or greater had a higher rate of mortality than patients with a mean blood glucose level of less than $10 \mathrm{mmol} / \mathrm{L}$ (OR 7.22; 95\% CI 1.08 to $48.29 ; \mathrm{P}=0.042$ ). Hyperglycemia was independently and significantly associated with mortality when adjusted for age and sex. Acute coronary events, renal failure, infection, hospital length of stay, ventilator use and ICU admissions were not associated with hyperglycemia. Only one-half of those with hyperglycemia, and none of the patients in the euglycemic group, received adequate glucose monitoring during the first two days of PN.

CONCLUSION: Hyperglycemia in noncritically ill inpatients receiving $\mathrm{PN}$ was found to be a risk factor for increased mortality.

Key Words: Hyperglycemia; Inpatients; Mortality; Nutrition; Outcome; Parenteral nutrition

乙 yperglycemia is a known mortality risk factor for intensive 1 care unit (ICU) patients (1). Research has been undertaken to identify the ideal range for glycemic control $(1,2)$. Additional research $(3,4)$ has revealed that the elevated mortality risk associated with hyperglycemia also exists among general ward hospital patients. Hyperglycemia is also a risk factor for adverse outcomes such as nosocomial infections and increased length of hospital stay (3).

Parenteral nutrition $(\mathrm{PN})$ is often a life-saving therapy. However, $\mathrm{PN}$ is a risk factor for hyperglycemia, which has been associated with poor outcomes $(4,5)$. Two recent studies $(4,5)$ examining mixed ICU and non-ICU PN patients revealed that hyperglycemia in PN patients is a risk factor for the development of infection, cardiac complications, acute renal failure and increased mortality.

\section{L'hyperglycémie associée à l'alimentation parentérale chez des patients hospitalisés qui ne sont pas gravement malades s'associe à une mortalité plus élevée}

\begin{abstract}
HISTORIQUE : L'hyperglycémie est un marqueur de mauvaises issues cliniques dans des études évaluant des patients hospitalisés gravement malades.

OBJECTIFS : Déterminer si le contrôle de la glycémie s'associe à des issues de santé, y compris les événements coronariens aigus, l'insuffisance rénale, l'infection, la durée d'hospitalisation, l'admission aux soins intensifs (SI), la sepsie et la mortalité chez des patients sous alimentation parentérale (AP), et comparer la norme actuelle de surveillance de la glycémie au Foothills Medical Centre (de Calgary, en Alberta) avec les lignes directrices 2009 de l'American Society of Parenteral and Enteral Nutrition.

MÉTHODOLOGIE : Les chercheurs ont procédé à l'examen rétrospectif du dossier de 100 patients hospitalisés (d'au moins 18 ans) qui n'étaient pas aux soins intensifs et qui ont été sous AP pendant au moins sept jours au Foothills Medical Centre.

RÉSULTATS : Dix-sept patients (17\%) avaient une glycémie moyenne d'au moins $10,0 \mathrm{mmol} / \mathrm{L}$. Les patients sous AP dont la glycémie moyenne était d'au moins $10 \mathrm{mmol} / \mathrm{L}$ présentaient un taux de mortalité plus élevé que ceux dont la glycémie était de $10 \mathrm{mmol} / \mathrm{L}$ ou moins (RRR 7,22; $95 \%$ IC 1,08 à 48,29; $\mathrm{P}=0,042$ ). L'hyperglycémie s'associait de manière indépendante et significative à la mortalité après rajustement compte tenu de l'âge et du sexe. Les événements coronariens aigus, l'insuffisance rénale, l'infection, la durée d'hospitalisation, le recours au respirateur et les admissions aux SI n'étaient pas liés à l'hyperglycémie. Seulement la moitié des patients hyperglycémiques, et aucun de ceux faisant partie du groupe euglycémique, ont reçu une surveillance pertinente de leur glycémie pendant les deux premiers jours d'AP.

CONCLUSION : Les chercheurs ont déterminé que l'hyperglycémie était un facteur de risque de mortalité accrue chez les patients sous AP qui n'étaient pas gravement malades
\end{abstract}

${ }^{1}$ Foothills Medical Centre, Alberta Health Services; ${ }^{2}$ Department of Community Health Services, University of Calgary; ${ }^{3}$ Division of Gastroeneterology, Alberta Health Services, Calgary, Alberta

Correspondence: Ms Sofia Sarkisian, Foothills Medical Centre, Nutrition Services, Alberta Health Services, 1403-29 Street Northwest, Calgary,

Alberta T2N 2T9. Telephone 403-944-2845, fax 403-944-1908, e-mail sofia.sarkisian@albertahealthservices.ca

Received for publication December 5, 2009. Accepted January 13, 2010 
TABLE 1

Patient characteristics

\begin{tabular}{lccc}
\hline & \multicolumn{2}{c}{ Patients } & \\
\cline { 2 - 3 } & $\begin{array}{c}\text { With } \\
\text { hyperglycemia } \\
(\mathbf{1 0} \mathbf{~ m m o l / L )} \\
(\mathbf{n = 1 7 )}\end{array}$ & $\begin{array}{c}\text { Without } \\
\text { hyperglycemia } \\
(<10 \text { mmol/L) } \\
\text { Ch=83) }\end{array}$ & P \\
\hline Age, years & $68(63-74)$ & $66(52-74)$ & 0.58 \\
Female sex, n (\%) & $9(53)$ & $43(52)$ & 1.0 \\
Body mass index, kg/m² & $26(24-29)$ & $23(20-27)$ & 0.15 \\
Diabetes, n (\%) & $6(35)$ & $9(11)$ & 0.02 \\
Comorbidities, n (\%) & $14(82)$ & $79(95)$ & 0.09 \\
Steroid use, n (\%) & $4(24)$ & $14(17)$ & 0.50 \\
Mean glucose level, mmol/L & $11.4(10.3-12.6)$ & $7.3(6.6-8.3)$ & $<0.01$ \\
Length of hospital stay, days & $35(28-51)$ & $30(22-50)$ & 0.42 \\
\hline
\end{tabular}

Data presented as median (interquartile range) unless indicated otherwise

amounts less than the maximum glucose oxidation rate (less than $4 \mathrm{mg} / \mathrm{kg} / \mathrm{min}$ ); and low doses of dextrose during PN initiation in at-risk patients $(100 \mathrm{~g} /$ day to $150 \mathrm{~g} /$ day or $2 \mathrm{mg} / \mathrm{kg} / \mathrm{min}$ to $3 \mathrm{mg} / \mathrm{kg} / \mathrm{min}$ ) (8). Additionally, these guidelines recommend measuring blood glucose levels three times daily to determine baseline levels and, subsequently, three times daily until blood glucose levels are consistently below $11 \mathrm{mmol} / \mathrm{L}$. It is unclear whether the ASPEN guidelines are actually instituted and/or effective in clinical practice.

To our knowledge, there have been no Canadian studies evaluating a possible association between PN-related hyperglycemia and health outcomes in noncritically ill patients receiving $\mathrm{PN}$.

We hypothesized that hospitalized noncritically ill PN patients with appropriate glycemic control have better clinical outcomes than patients with uncontrolled hyperglycemia.

The objective of the present study was to identify whether there is an association between glycemic control and health outcomes including hospital length of stay, ICU admission, renal failure, sepsis, acute coronary events and mortality among noncritically ill inpatients receiving PN. Furthermore, we sought to compare the current practice for glucose monitoring at the Foothills Medical Centre (Calgary, Alberta) with the ASPEN guideline recommendations (8).

\section{METHODS}

The current study was a retrospective chart review of a convenience sample of 100 adult medical and surgical inpatients 18 years of age or older at the Foothills Medical Centre. The Foothills Medical Centre is the largest quaternary care centre in Southern Alberta, providing complex acute medical and surgical care to approximately 1.2 million residents of Calgary and surrounding communities in southern Alberta. To meet the inclusion criteria, patients were required to receive $\mathrm{PN}$ for a minimum of seven days, and that the indication for PN was approved by the attending inpatient dietitian. Some patients received both oral and PN nutrition; however, the exact number of oral calories consumed was not documented because this information was not available in the hospital charts. Patients admitted to ICUs (cardiovascular ICU and medical/surgical ICU) before $\mathrm{PN}$ initiation, palliative patients, patients on
TABLE 2

Parenteral nutrition prescriptions

\begin{tabular}{|c|c|c|c|}
\hline \multirow[b]{2}{*}{$\begin{array}{l}\text { Parenteral nutrients } \\
\text { (per day) }\end{array}$} & \multicolumn{2}{|c|}{ Patients } & \multirow[b]{2}{*}{$\mathbf{P}$} \\
\hline & $\begin{array}{c}\text { With } \\
\text { hyperglycemia } \\
(\geq 10 \mathrm{mmol} / \mathrm{L})(\mathrm{n}=17)\end{array}$ & $\begin{array}{c}\text { Without } \\
\text { hyperglycemia } \\
\text { (<10 mmol/L) }(\mathrm{n}=83)\end{array}$ & \\
\hline Kcal & $1800 \pm 416$ & $1713 \pm 337$ & 0.46 \\
\hline $\mathrm{Kcal} / \mathrm{kg}$ & $24 \pm 4$ & $28 \pm 23$ & 0.18 \\
\hline Dextrose, $\mathrm{g}$ & $259 \pm 76$ & $249 \pm 65$ & 0.69 \\
\hline Fat, $g$ & $52 \pm 11$ & $48 \pm 10$ & 0.16 \\
\hline Protein, $\mathrm{g}$ & $100 \pm 24$ & $93 \pm 19$ & 0.20 \\
\hline
\end{tabular}

Data presented as mean \pm SD unless indicated otherwise

hemodialysis and those receiving intradialytic PN were excluded. The list of PN patient candidates was obtained from the central pharmacy. Information collected from the charts included patient demographics, details regarding the length of hospital stay, duration of PN, comorbidities and oral calories consumed while on PN (Tables 1, 2, 3 and 4).

Hyperglycemia was defined as mean blood glucose level of $10 \mathrm{mmol} / \mathrm{L}$ or greater, which was based on previous work in this area (5). Blood glucose values were assessed using either finger-prick glucometer (LifeScan, Canada) readings or line draw as part of the standard initial PN blood work. The mean blood glucose level was calculated for each patient based on the total number of readings taken during the first nine days of receiving PN. All health outcomes were documented during receipt of PN. Catheter or noncatheter infection was identified as an elevated white blood cell count in addition to one or more of the following: positive blood cultures, chest $\mathrm{x}$-ray suggestive of pneumonia, positive urine culture, postoperative wound infection and the use of antibiotics. Renal failure was defined as a serum creatinine level of greater than $130 \mathrm{mmol} / \mathrm{L}$. Acute coronary events were diagnosed by electrocardiogram, troponin level and/or cardiology confirmation.

Assessment of overfeeding was made by comparing the PN prescription with the estimated energy and protein needs based on either a dietitian-estimated Harris-Benedict equation or a caloric range of $25 \mathrm{kcal} / \mathrm{kg}$ to $35 \mathrm{kcal} / \mathrm{kg}$. Because the Foothills Medical Centre does not have a centralized PN team that administers total PN, the medical team responsible for the patient's care is charged with ensuring that glycemic protocols are implemented and/or adhered to. The PN formula at the Foothills Medical Centre is provided as a total nutrient admixture (' 3 in 1'), which means that the lipid, dextrose, electrolytes, vitamins and trace elements are contained in one bag. Each prescription is unique in that $\mathrm{PN}$ is ordered based on a 'dosing weight' (ie, kcal/kg/day; protein g/kg/day; lipid g/kg/day).

The present study was approved by the Conjoint Health Research Ethics Board, Faculty of Medicine and the University of Calgary (Calgary, Alberta).

\section{Statistical analysis}

Descriptive analysis was performed using $\chi^{2}$, Fisher's exact, Mann-Whitney or Kruskal Wallis tests as required. Logistic regression models were used to identify the age- and sexadjusted predictors of mortality and other adverse outcomes. A two-sided $\mathrm{P}<0.05$ was considered to be statistically significant. 


\begin{tabular}{|c|c|c|c|c|}
\hline \multirow[b]{2}{*}{ Characteristic } & \multicolumn{2}{|c|}{ Patients } & \multirow[b]{2}{*}{ OR (95\% Cl), P } & \multirow[b]{2}{*}{ Adjusted $\mathrm{OR}^{*}(95 \% \mathrm{Cl}), \mathrm{P}$} \\
\hline & $\begin{array}{c}\text { With } \\
\text { hyperglycemia } \\
(\geq 10 \mathrm{mmol} / \mathrm{L})(\mathrm{n}=17)\end{array}$ & $\begin{array}{c}\text { Without } \\
\text { hyperglycemia } \\
(<10 \mathrm{mmol} / \mathrm{L})(\mathrm{n}=83)\end{array}$ & & \\
\hline Renal failure, $\mathrm{n}(\%)$ & $3(18)$ & $10(12)$ & $1.56(0.38-6.41), 0.53$ & 1.89 (0.41-8.64), 0.41 \\
\hline Infection, n (\%) & $7(41)$ & $37(45)$ & 0.87 (0.30-2.51), 0.80 & 0.87 (0.30-2.51), 0.80 \\
\hline Intensive care unit admission, $\mathrm{n}(\%)$ & $1(6)$ & $9(11)$ & $0.51(0.06-4.35), 0.54$ & 0.51 (0.06-4.33), 0.54 \\
\hline Per cent change of length of hospital stay & N/A & N/A & $17(-16-65), 0.35^{\dagger}$ & 17 (-17-67), $0.36^{\dagger}$ \\
\hline Mortality, n (\%) & $3(18)$ & $3(4)$ & 5.71 (1.04-31.22), 0.04 & 7.22 (1.08-48.29), 0.04 \\
\hline
\end{tabular}

Continuous data are presented as median (Interquartile range [IQR]); categorical data are presented as $n$ (\%). *Adjusted for age and sex (length of hospital stay was transformed to the logarithmic form); ${ }^{\dagger}$ Presented are the exponentiated coefficient of the linear regression analysis to predict hospital length of stay as percentage increase/decrease $(95 \% \mathrm{CI})$. N/A Not applicable

TABLE 4

Observed frequency of glucose monitoring according to hyperglycemia and survival

\begin{tabular}{|c|c|c|c|c|c|c|c|c|}
\hline \multirow[b]{2}{*}{ Characteristic } & \multirow{2}{*}{$\begin{array}{l}\text { ASPEN-recommended } \\
\text { frequency, } \mathbf{n}\end{array}$} & \multirow{2}{*}{$\begin{array}{l}\text { Measurement } \\
\text { frequency }\end{array}$} & \multicolumn{3}{|c|}{ Hyperglycemia* } & \multicolumn{2}{|c|}{ Patients } & \multirow[b]{2}{*}{$\mathbf{P}^{\ddagger}$} \\
\hline & & & Without & With & $\mathbf{P}^{\dagger}$ & Deceased & Survived & \\
\hline Glucose monitoring in first $48 \mathrm{~h}$ & 8 & $4(2-7)$ & $3(2-6)$ & $8(5-8)$ & 0.003 & $5(3-8)$ & $4(2-7)$ & 0.87 \\
\hline Glucose monitoring at days 3-9 & $\begin{array}{c}\text { At least } 3 \text { times daily } \\
\text { until }<11 \mathrm{mmol} / \mathrm{L}\end{array}$ & $6(3-18)$ & $6(2-12)$ & $21(18-27)$ & $<0.001$ & $5(0-20)$ & $6(3-17)$ & 0.68 \\
\hline
\end{tabular}

Data presented as median (interquartile range) unless indicated otherwise. *Hyperglycemia was defined as having any blood glucose measurement of 10 mmol/L or greater; ${ }^{\dagger}$ Comparison of the frequency of measurements between the hyperglycemia group and the group with no hyperglycemia; ${ }^{\ddagger}$ Comparison of the frequency of measurements between deceased and survived patients. ASPEN American Society of Parenteral and Enteral Nutrition

\section{RESULTS}

The indications for PN are shown in Figure 1. Seventeen (17\%) of the patients had one or more blood glucose level readings of $10.0 \mathrm{mmol} / \mathrm{L}$ or greater (Table 1 ). No demographic or clinical differences between patients with or without hyperglycemia were observed, except for the prevalence of diabetes $(\mathrm{P}=0.02)$ (Table 1).

The macronutrient composition of the PN prescriptions (ie, the average daily macronutrients: grams of fat, carbohydrate and protein, and total calories) are reported in Table 2. There were no differences in the quantities of macronutrients consumed between those with or without hyperglycemia. Each patient was monitored by an inpatient dietitian, and none were overfed based on comparisons with the dieticians' initial assessment.

Patients in the highest blood glucose quartile $(10 \mathrm{mmol} / \mathrm{L}$ or greater) had a higher rate of mortality than the other patients (OR 5.71 95\% CI 1.04 to 31.22; $\mathrm{P}=0.04$ ) (Figure 2, Table 3). Adjusted for age and sex, hyperglycemia was independently associated with mortality (OR $7.22,95 \%$ CI 1.08 to 48.29 ; $\mathrm{P}=0.04$ ). Controlling for diabetes did not alter our findings (OR 9.3; 95\% CI 1.24 to $70.0 ; \mathrm{P}=0.03$ ). The frequencies of acute coronary events, renal failure, infection or length of hospital stay were not associated with the degree of hyperglycemia (Table 3).

In the present study, a median of four glucose measurements were taken during the first $48 \mathrm{~h}$ of $\mathrm{PN}$ (interquartile range two to seven measurements), which was significantly lower than the recommended frequency $(\mathrm{P}<0.001)$ (Table 4). Patients with hyperglycemia had their blood glucose monitored more frequently in both the first $48 \mathrm{~h}(\mathrm{P}=0.003)$ (Figure 3$)$ and in the following week $(\mathrm{P}<0.001)$ (Figure 4$)$ compared with patients who did not have hyperglycemia (Table 4). There was no association between the frequency of glucose monitoring and mortality in the first $48 \mathrm{~h}(\mathrm{P}=0.87)$ or in the following week $(\mathrm{P}=0.68)$ (Table 4).

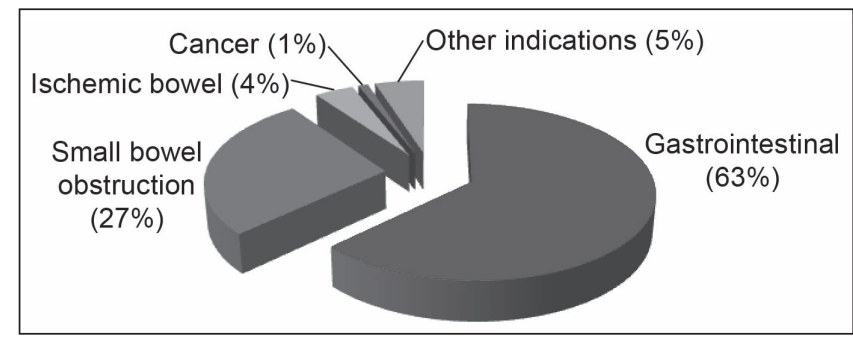

Figure 1) Indications for parenteral nutrition. Gastrointestinal includes ileus, Crohn's disease, ulcerative colitis, fistula, upper/lower gastorintestinal bleed, perforated esophagus, celiac disease, radiation enteritis and necrotizing fasciitis. Other indications include surgeon preference to protect anastamosis and avoid feeding tube placement

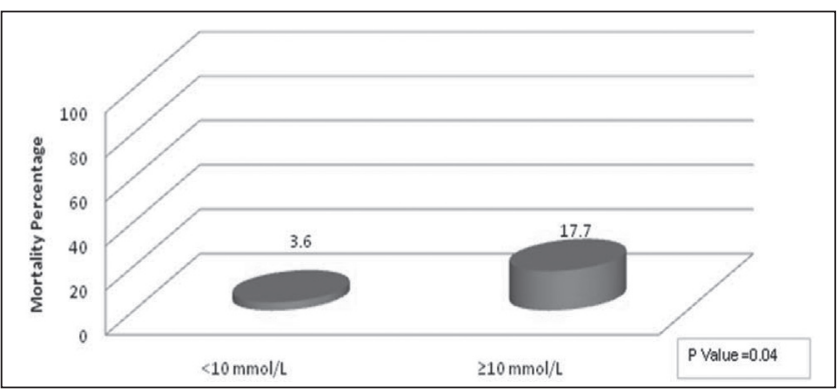

Figure 2) Mortality rates according to mean glucose levels

\section{DISCUSSION}

While confirming previous reports that hyperglycemia (blood glucose level greater than $10 \mathrm{mmol} / \mathrm{L}$ ) is a risk factor for mortality $(1,4,5)$, the present study is the first to report this association strictly among noncritically ill patients receiving PN. Furthermore, we demonstrated that hyperglycemia is a risk factor for increased mortality among a sample of Canadian 


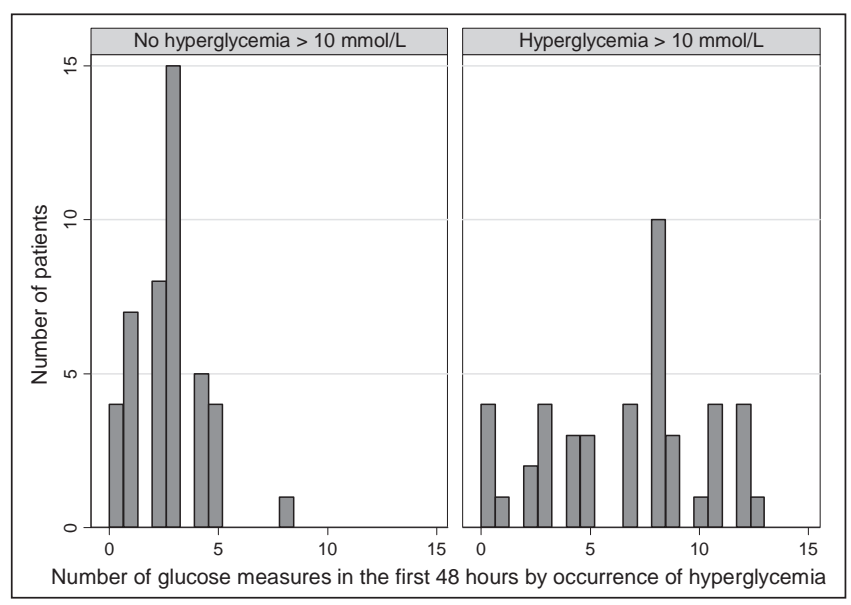

Figure 3) Number of glucose measurements taken in the first $48 \mathrm{~h}$ according to hyperglycemia occurrence

inpatients. The causes of hyperglycemia in the present study did not appear to be due to overfeeding because the absolute amount of nutrition provided as per dietitian assessment was appropriate.

The optimal target range for blood glucose control in the critically ill setting has been a topic of controversy for some time. Until recently, the guidelines for glycemic control published in the study by van den Berghe et al (1) have been adopted in critical care units. The van den Berghe study - a randomized controlled trial comparing intensive insulin therapy (maintenance of blood glucose between $4.4 \mathrm{mmol} / \mathrm{L}$ and $6.1 \mathrm{mmol} / \mathrm{L}$ ) and conventional treatment (maintenance of glucose at a level between $10.0 \mathrm{mmol} / \mathrm{L}$ and $11.1 \mathrm{mmol} / \mathrm{L}$ ) among intensive care patients - demonstrated improved mortality with intensive insulin therapy. However, subsequent studies $(2,9)$ have reminded clinicians that hypoglycemia, which can occur during intensive insulin therapy, is also a risk factor for mortality. Recently, the Normoglycaemia in Intensive Care Evaluation and Survival Using Glucose Algorithm Regulation (NICE-SUGAR) study group (2) revisited the issues surrounding optimal glucose control in critical care settings. Results from this large, randomized, controlled international study showed that a blood glucose target of $10 \mathrm{mmol} / \mathrm{L}$ or lower resulted in lower mortality than more intensive glycemic control with the target of $6.1 \mathrm{mmol} / \mathrm{L}$ previously suggested by van den Berghe et al (1). It is believed that, in part, the adverse effects noted with more rigorous glucose control (1) have been attributed to more frequent occurrences of hypoglycemia (9). The high number of deaths that occurred in the NICE-SUGAR study were predominantly from cardiovascular causes, suggesting that reducing blood glucose levels by the administration of insulin may affect the cardiovascular system (10). We found that blood glucose levels of greater than $10 \mathrm{mmol} / \mathrm{L}$ were associated with increased mortality in noncritically ill inpatients receiving PN. Therefore, given the findings of the NICE-SUGAR study (2), it may be reasonable to apply a similar target of glycemic control (lower than $10 \mathrm{mmol} / \mathrm{L}$ ) to $\mathrm{PN}$ patients.

Patients receiving PN are at higher risk of hyperglycemia than patients who are fed via the gastrointestinal tract (1). Therefore, patients receiving $\mathrm{PN}$ require glycemic monitoring when $\mathrm{PN}$ is started and, again, when the PN prescription is modified. Hyperglycemia among PN patients can be managed by decreasing the glucose infusion rate and/or with basal and short-acting insulin.

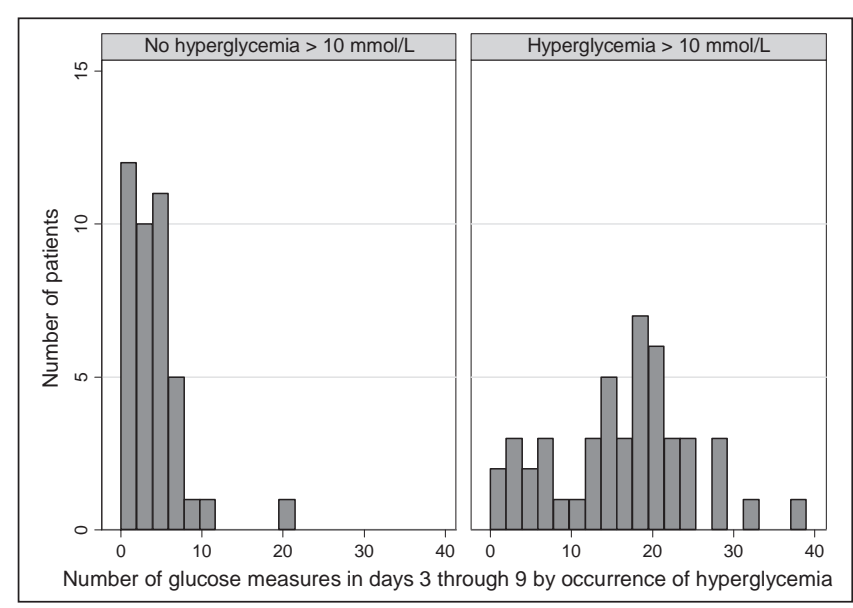

Figure 4) Number of glucose measurements taken in days 3 through 9 according to hyperglycemia occurrence

The ASPEN glucose monitoring recommendations were not followed for most of our patients. The ASPEN guidelines recommend that glucose be monitored every $6 \mathrm{~h}$ after initiation of PN (8) and, therefore, eight times in the first $48 \mathrm{~h}$. It is possible that if the ASPEN guideline recommendations were followed, the higher mortality could have been averted; however, this is only speculation that warrants assessment. We noted no association between the frequency of glucose measurements and mortality. This lack of association was likely due to the limited sample size and the retrospective study design. Whether increased glucose monitoring in PN patients improves mortality merits testing in a randomized controlled trial.

Based on our findings and those of the NICE-SUGAR study (2), Cheung et al (4) and Lin et al (5), a glucose level of lower than $11 \mathrm{mmol} / \mathrm{L}$ recommended by the ASPEN guidelines as an indicator of acceptable blood glucose levels may need to be revised. However, it is not sufficient to simply recommend a range of blood glucose values to improve outcomes. The recommended blood glucose level needs to be accompanied by an effective insulin dosing strategy that is workable in general medical and surgical units. The NICE-SUGAR study (2) followed a specific treatment algorithm that is potentially generalizable to patients receiving enteral and, possibly, PN. To the best of our knowledge, treatment algorithms for insulin dosing are not currently available; consequently, they need to be developed and rigorously tested in patients receiving PN. Additionally, further research is needed to pinpoint the optimal glucose level for identifying those at higher risk of adverse outcomes. Additional guidelines are needed for the following: glucose monitoring beyond the initiation phase; the nature of supplementary glucose monitoring indicated after glucose and/or energy intakes are increased; and the optimal frequency of monitoring needed after a patient records several measurements below $11 \mathrm{mmol} / \mathrm{L}$.

In contrast to our study, others $(1,5)$ have documented higher rates of medical complications (eg, infection, cardiac complications, acute renal failure and respiratory failure) associated with higher blood glucose levels. The lack of association between hyperglycemia and these negative outcomes could be a consequence of the small sample size, the differences in our populations (our sample was limited to non-ICU patients) and/or selection bias due to the retrospective study design. 
However, we believe that further prospective studies are needed to assess the association of hyperglycemia and the nature and degrees of comorbidities with their impact on mortality.

The mechanism of harm to various cells and organ systems as a result of hyperglycemia has not been defined, and speculation has focused on the immune system, inflammatory mediators and vascular responses. Hyperglycemia alters the activity of phagocytes because it interferes with neutrophil and monocyte functions including adherence, chemotaxis and phagocytosis (11,12). Similarly, acute hyperglycemia has many effects on the cardiovascular system. Hyperglycemia may impair ischemic preconditioning, which is a protective mechanism for ischemic insult (13). Additionally, hyperglycemia may reduce coronary collateral blood flow leading to increases in infarct size (13), and may induce cardiac myocyte death via apoptosis (14).

Regarding our second objective - to determine the current standard of care for glucose monitoring in non-ICU patients receiving $\mathrm{PN}$ - we found that our patients, both with and without hyperglycemia, were undermonitored. Greater attention to glucose monitoring among recipients of $\mathrm{PN}$ may result in shorter durations of hyperglycemia and earlier initiation of appropriate glucose-lowering therapies.

\section{Strengths}

Our finding of increased mortality associated with hyperglycemia is similar to the results of two previous studies $(4,5)$ conducted in Asia and Australia. These findings may provide justification to revise the current glucose monitoring guidelines for PN patients, and may help inform the development of insulin provision guidelines for PN patients.

\section{Limitations}

Weaknesses of the present cohort study include the singlecentre, retrospective design and the limited sample size that may have mitigated the statistical significance of the findings. Given the study design, we can only speculate on the mechanism of hyperglycemia as it relates to mortality, and that the finding of an association could be due to uncontrolled confounding. It is conceivable that hyperglycemia represents a metabolic marker of an underlying disease process that

\section{REFERENCES}

1. van den Berghe $G$, Wouters P, Weekers F, et al. Intensive insulin therapy in the critically ill patients. N Engl J Med 2001;345:1359-67.

2. Finfer S, Chittock DR, Su SY, et al. Intensive versus conventional glucose control in critically ill patients. N Engl J Med 2009;360:1283-97.

3. Umpierrez GE, Isaacs SD, Bazargan N, You X, Thaler LM, Kitabchi AE. Hyperglycemia: An independent marker of in-hospital mortality in patients with undiagnosed diabetes. J Clin Endocrinol Metab 2002;87:978-82.

4. Cheung NW, Napier B, Zaccaria C, Fletcher JP. Hyperglycemia is associated with adverse outcomes in patients receiving total parenteral nutrition. Diabetes Care 2005;28:2367-71.

5. Lin LY, Lin HC, Lee PC, Ma WY, Lin HD. Hyperglycemia correlates with outcomes in patients receiving total parenteral nutrition. Am J Med Sci 2007;333:261-5.

6. Boucher JL, Swift CS, Franz MJ, et al. Inpatient management of diabetes and hyperglycemia: Implications for nutrition practice and the food and nutrition professional. J Am Diet Assoc 2007;107:105-11

7. Leahy JL. Insulin management of diabetic patients on general medical and surgical floors. Endocr Pract 2006;12(Suppl 3):86-90. predisposes toward greater mortality. Therefore, interventional studies of PN patients with various degrees of glycemic control are required to identify the optimum glucose level for improved morbidity and mortality.

To date, data regarding strategies to optimize glucose control in diabetic and nondiabetic patients with hyperglycemia beyond the recommendation to simply check blood glucose levels - are unavailable. In monitored settings such as critical care units, given the one-on-one care provided and attention to more detailed clinical and laboratory changes, potential adherence to insulin dosing strategies in a timely manner is more feasible than on a day-to-day basis in inpatient units. Potentially, there is role for a more team-based approach to glycemic control among ICU, mixed ICU and, now, non-ICU populations, particularly because there is much evidence supporting harm due to poor glycemic control.

\section{CONCLUSIONS}

Based on our sample population, hyperglycemia is a risk factor for increased mortality in noncritically ill inpatients receiving PN. Further work is needed to determine whether mortality rates are improved when glucose is monitored more closely in noncritically ill inpatients receiving $\mathrm{PN}$ and when hyperglycemia is managed via decreased glucose infusion rates or the administration of insulin. Further research is needed to determine the optimum glucose targets. There is a need to develop a protocol for blood glucose monitoring and insulin administration to decrease mortality risk for $\mathrm{PN}$ patients. In light of the concerns associated with hyperglycemia, we suggest that the ASPEN glucose monitoring guidelines be revised and enhanced to specify the frequency of glucose measurements after the initiation of PN.

Based on the similarity of our results to other studies, the present study reinforces the need to conduct a sufficiently powered prospective, randomized controlled trial of glycemic control via decreased glucose infusion rates and/or insulin infusion, to assess the relationship between hyperglycemia and health outcomes. Additionally, determining the optimal mode of insulin administration (ie, insulin drip versus intermittent basal-bolus plus correction dosages) to improve outcomes is required.

8. Sacks GS, Mayhew S, Peterson C. Parenteral nutrition implementation and management. In: Merritt R, ed. ASPEN Nutrition Support Practice Manual, 2nd edn. Silver Spring: American Society for Parenteral and Enteral Nutrition, 2009:114-5.

9. Griesdale DE, de Souza RJ, van Dam RM, et al. Intensive insulin therapy and mortality among critically ill patients: A meta-analysis including NICE-SUGAR study data. CMAJ 200;180:821-7.

10. Dunbar JC, O'Leary DS, Wang G, Wright-Richey J. Mechanisms mediating insulin-induced hypotension in rats. A role for nitric oxide and autonomic mediators. Acta Diabetol 1996;33:263-8.

11. Leibovici L, Yehezkelli Y, Porter A, Regev A, Krauze I, Harell D. Influence of diabetes mellitus and glycaemic control on the characteristics and outcome of common infections. Diabet Med 1996;13:457-63.

12. Clement S, Braithwaite SS, Magee MF, et al. Management of diabetes and hyperglycemia in hospitals. Diabetes Care 2004;27:553-91.

13. Kersten JR, Schmeling TJ, Orth KG, Pagel PS, Warltier DC. Acute hyperglycemia abolishes ischemic preconditioning in vivo. Am J Physiol 1998;275:H721-5.

14. Ceriello A, Quagliaro L, D’Amico M, et al. Acute hyperglycemia induces nitrotyrosine formation and apoptosis in perfused heart from rat. Diabetes 2002;51:1076-82. 


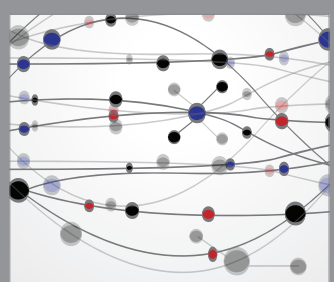

The Scientific World Journal
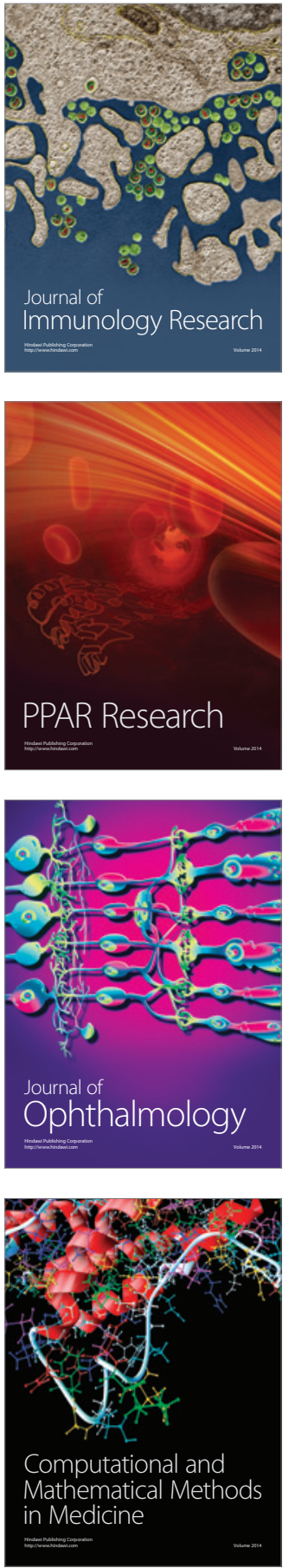

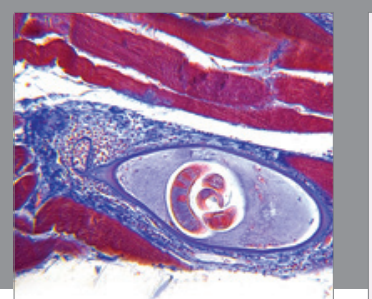

Gastroenterology Research and Practice

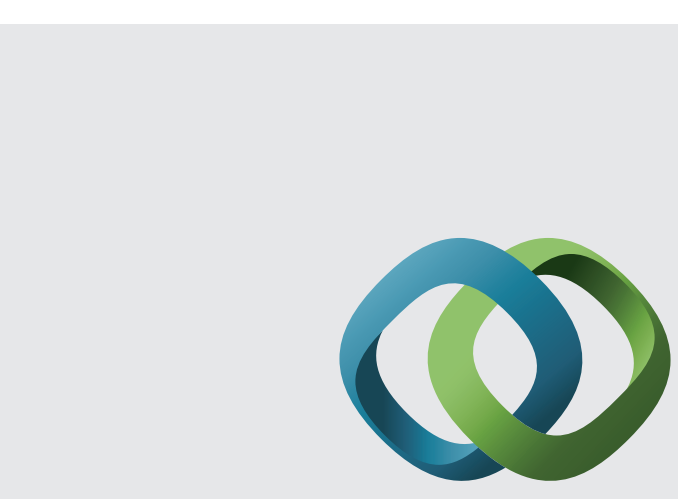

\section{Hindawi}

Submit your manuscripts at

http://www.hindawi.com
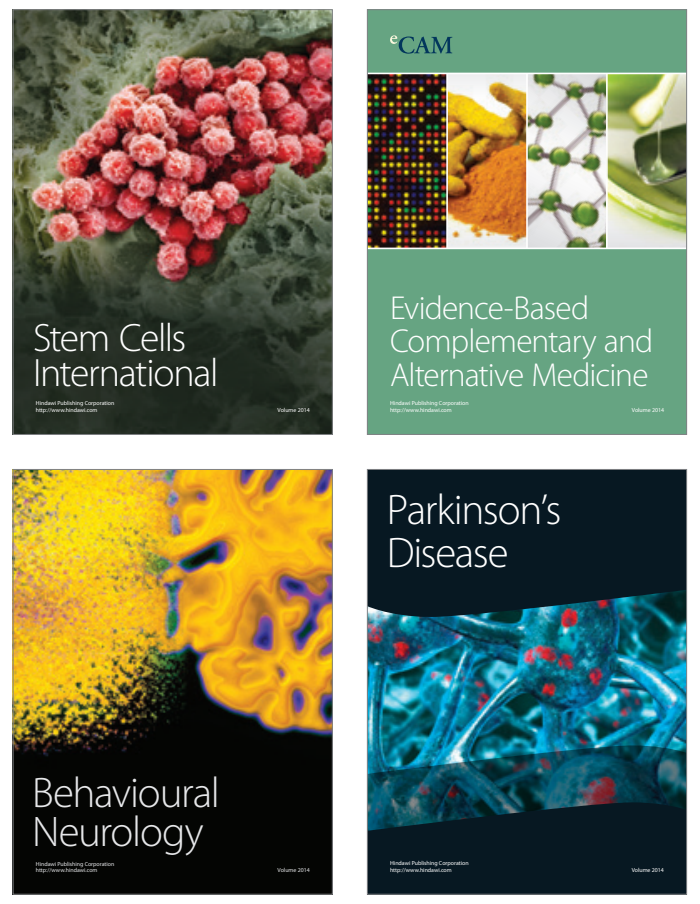
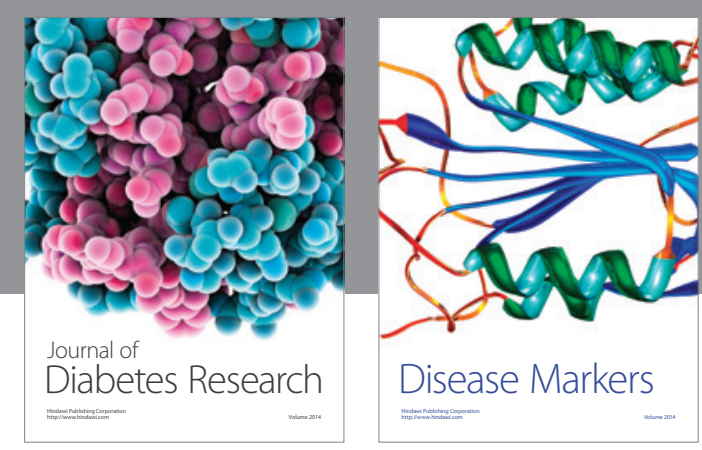

Disease Markers
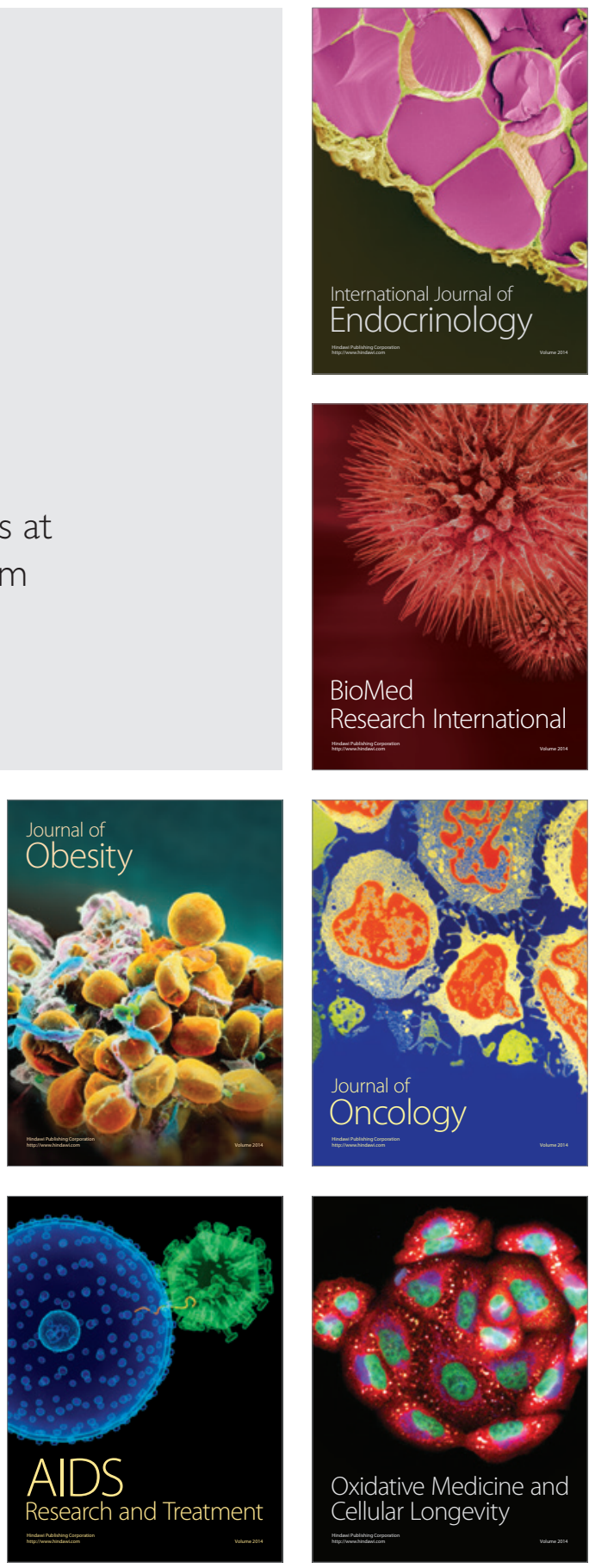